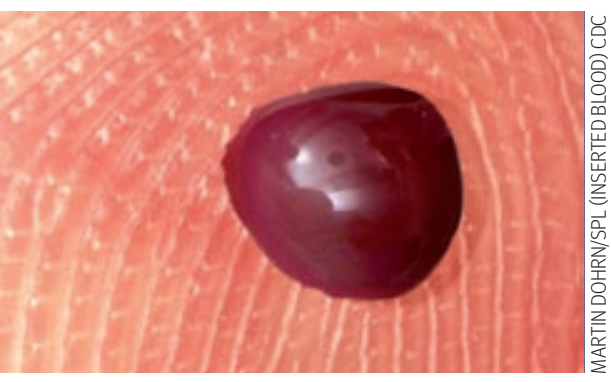

\section{SELF MONITORING IN DIABETES}

\section{Useful in which patients?}

The conclusion of the randomised trial reported by Farmer et $\mathrm{al}^{1}$ is in line with a recent systematic review of randomised trials (1000 patients, three trials) and observational studies (60 000 patients, 13 studies), ${ }^{2}$ which shows that only when the average starting $\mathrm{HbA}_{1 \mathrm{c}}$ is above $8 \%$ do studies consistently show benefit of self monitoring.

The inference that self monitoring may be beneficial where control is poor is just common sense. That it is difficult to show benefit when control is already pretty good is also common sense-there is no sensitivity to show a difference even if there were one.

A different way of reporting results of trials like this would be interesting. Our interest is not in the average patient, since few patients are average: what we require is to know the number of patients who showed improvement (however defined, or perhaps at several levels of $\mathrm{HbA}_{1 \mathrm{c}}$ ) versus the number showing no change or an increase in $\mathrm{HbA}_{1 \mathrm{c}}$, as has been done before. ${ }^{3}$

Generalised policy decisions should not be based on data like these.

Extrapolating averages from trials into health economic models does disservice to patients and professionals in several ways. A more useful approach would be some operational and other research to identify the patients who would benefit most from self monitoring and the best way to engage them in actively helping themselves. This would build on professional skill and responsibility.

Where doctors make their own decisions, the results have been terrific, especially in clinical outcomes with major consequence. They did it by deciding which patients with type 2 diabetes would benefit from self monitoring, and prescribing self monitoring in those patients. ${ }^{4}$

Andrew Moore editor, Bandolier Sheena Derry senior research associate, Grace McGeogh medical student, Pain Research Nuffield Department of Anaesthetics, University of Oxford, The Churchill, Oxford OX3 7LJ

andrew.moore@pru.ox.ac.uk

Competing interests: The authors have written a recently published systematic review on this topic.

1 Farmer A, Wade A, Goyder E, Yudkin P, French D, Craven $A$, et al, on behalf of the Diabetes Glycaemic Education and Monitoring Trial Group. Impact of self monitoring of blood glucose in the management of patients with non-insulin treated diabetes: open parallel group randomised trial. BMJ 2007;335:132-6. (21 July.)

2 McGeoch G, Derry S, Moore RA. Self-monitoring of blood glucose in type-2 diabetes: what is the evidence? Diabetes Metab Res Rev 2007; Epub ahead of print.

3 Guerci B, Drouin P, Grange V, Bougneres P, Fontaine $P$, Kerlan V, et al. Self-monitoring of blood glucose significantly improves metabolic control in patients with type 2 diabetes mellitus: the Auto-Surveillance Intervention Active (ASIA) study. Diabetes Metab 2003;29:587-94.

4 Martin S, Schneider B, Heinemann L, Lodwig V, Kurth H-J, $\mathrm{Kolb} \mathrm{H}$, et al. Self-monitoring of blood glucose in type 2 diabetes and long-term outcome: an epidemiological cohort study. Diabetologia 2006;49:271-8.

\section{Education seems to work better}

The article by Farmer et al reinforces our experiences in practice. ${ }^{1}$ We have not prescribed testing strips routinely to patients with stable type 2 diabetes for the past three years. Aggressive diabetic management based on principles of patient education, development of trust between trained diabetes nurses and the patient, and early use of oral agents to achieve target $\mathrm{HbA}_{1 \mathrm{c}}$ levels have led to gratifyingly good outcome measures in our 3000 patient urban practice.

We discourage the use of self monitoring for several reasons: expense of testing strips and equipment, the anxiety generated by small variations in results and the subsequent medical time pressures in dealing with these, equipment failure, and the lack of evidence of any benefit. We have had pressure from hospital consultants, patients themselves, and pressure groups to provide testing strips, but we have firmly stuck to our guns. In the current state of knowledge, nothing would persuade us to go back to encouraging or supporting routine self monitoring in stable type 2 diabetes: our results are too good to justify the change.

Anthony J Lister general practitioner, Old Palace Medical Practice, Norwich NR2 4JA

anthony.lister@nhs.net

Competing interests: None declared.

1 Farmer A, Wade A, Goyder E, Yudkin P, French D, Craven $A$, et al, on behalf of the Diabetes Glycaemic Education and Monitoring Trial Group. Impact of self monitoring of blood glucose in the management of patients with non-insulin treated diabetes: open parallel group randomised trial. BMJ 2007;335:132-6. (21 July.)

\section{Let me own my disease}

As has been pointed out by several responders, the trial of Farmer et al was flawed in that those in the "intensive testing" group were not given the information to act on the results of their tests to bring their blood glucose down (take exercise), nor were they encouraged to use the results of the test to modify their diets to achieve greater control. ${ }^{12}$ On the contrary, they were encouraged to maintain their regimens.

Therefore I find the contention that self monitoring of blood glucose is not beneficial and the attitude of some of the medical profession towards their diabetic patients extremely arrogant and ill founded. It led me to think about how I would feel if I were refused strips and treated like a child with the diabetes specialist nurse prescribing my regimen-in effect, it would take away my "ownership" of the disease.

Surely it is possible for doctors to prescribe for motivated patients who will take advantage of the strips to modify their regimens accordingly and prove the worth of the prescription by saving the NHS money in the long run. There will, of course, be many patients who cannot cope with the necessary hard work (because it is hard work) and who would prefer to have their diabetes managed by the medical profession, but please do not deny the wherewithal to those who are both motivated and able to use the results.

Patti D Evans administrator, Lescudjack Centre, Penzance, Cornwall TR18 3PE

patti.evans@btconnect.com

Competing interests: None declared.

1 Farmer A, Wade A, Goyder E, Yudkin P, French D, Craven $A$, et al, on behalf of the Diabetes Glycaemic Education and Monitoring Trial Group. Impact of self monitoring of blood glucose in the management of patients with non-insulin treated diabetes: open parallel group randomised trial. $B M$ J 2007;335:132-6. (21 July.) 
2 Rapid responses. Impact of self monitoring of blood glucose in the management of patients with non-insulin treated diabetes. bmj.com 2007 www.bmj.com/cgi/ eletters/335/7611/132

\section{Authors' reply}

We agree with Moore et al that the results of a clinical trial should be interpreted in the context of an individual patient. Our trial of self monitoring of blood glucose does not exclude the possibility of a clinically important benefit for specific patient subgroups. While we welcome the improvements in care offered by Lister to his patients, personalising care on the basis of clinical judgment remains of critical importance. We agree with Evans that clinical judgment should be guided, rather than prescribed, by evidence from randomised trials. However, she has misunderstood the design of the more intensive self monitoring intervention where patients were provided with training and support to interpret readings and revise behavioural goals to reach treatment targets. ${ }^{1}$

We take issue with Moore et al on several points. Firstly, it is not self evident that self monitoring will help where control is poor. We agree that the benefits of monitoring are self evident, but the relative benefits of self monitoring compared with repeated $\mathrm{HbA}_{1 \mathrm{c}}$ measurements are unclear. We plan to explore this in exploratory subgroup analyses.

Secondly, we disagree with their comments about use of health economic models. The cost implications of routinely recommending self monitoring for all non-insulin treated patients with type 2 diabetes need to be carefully considered, and it would be unethical not to do so.

Finally, it is disappointing that they turn to a cohort study, which is likely to be confounded by unmeasured, and unmeasurable, individual characteristics, to claim "terrific" results for self monitoring. ${ }^{2}$ Randomised trials remain the gold standard for assessing an intervention.

Andrew Farmer lecturer, Department of Primary Health Care, University of Oxford, Oxford OX2 7LF

Patricia Yudkin reader, School of Health and Related

Research, University of Sheffield

Elizabeth Goyder reader, Division of Public Health and

Primary Care, University of Oxford

Andrew Neil professor,

On behalf of the DiGEM Trial Group

Competing interests: None declared.

1 Farmer A, Wade A, French D, Goyder E, Kinmonth AL, Neil A. The DiGEM trial protocol-a randomised controlled trial to determine the effect on glycaemic control of different strategies of blood glucose self-monitoring in people with type 2 diabetes. BMC Fam Pract 2005,6:25.
2 Martin S, Schneider B, Heinemann L, Lodwig V, Kurth H-J, et al. Self-monitoring of blood glucose in type 2 diabetes and long-term outcome: an epidemiological cohort study. Diabetologia 2006;49:271-8.

\section{INSOLVENT HOSPITALS}

\section{It's not just whole hospitals}

Ham points out the importance of the choices the government makes around failing hospitals. ${ }^{1}$ Almost every proposed reconfiguration will provoke local opposition from the people who live next door to the hospital. But what should matter for serious decision makers is not the views of the IMBYs (everyone wants a hospital "in my back yard") but a rational standard of provision. For example, we might try to maintain general hospital levels of service in a certain travel time of the population (with perhaps a much less stringent limit for services that require substantial critical mass).

But this sort of analysis is rarely seen in the context of reconfiguration. For England we recently found that if we set an acceptable access standard of 30 minutes' travel by road (actually quite a stringent target) we find that about 7\% of the English population have no provision (this is mostly the rural fringes), but a remarkable $55 \%$ of the population have three or more hospitals available. Ten per cent have more than 10 choices at this standard of provision.

Thus there are parts of the country where even the complete closure of a major hospital would not leave a black hole for provision, and the government should stand up to the IMBYs. Many of the most controversial proposed reconfigurations are in well provisioned parts of the country, where the proposed changes could give people substantially better quality provision at an only marginally less convenient location. Stephen Black management consultant London SW1W 9SR stephen.black@paconsulting.com

Competing interests: None declared.

1 Ham C. What to do with insolvent hospitals. BMJ 2007;335:170. (28 July.)

\section{LIFE SAVING GENERAL PRACTICE}

\section{Perhaps, if we work less hard}

I agree with Heath, but the reality of being a general practitioner (GP) can quickly erode noble sentiments. ${ }^{1}$ In my 20 years as a full time GP I very much wanted to work by the tenets in this article. But being a full time GP with an average list is hard, hard work. It is not just easy to get it wrong: getting it wrong, very wrong, is part of the process.

The work rate of most GPs is damaging to both patients and doctors. That work rate or "busyness" is often used as an excuse for "getting it wrong." However, it is that work rate which makes GPs so economical. To complete that argument, GPs are efficient and cheap because they half do things. Usually we get away with it and we will use our "luck" to rationalise our failures. But that is changing, and in my latter years I saw standards rising and GPs trying much harder to do a better job. The current system is not designed to deliver that service. Add in the internet and rising patient expectations, and the current system will probably fail.

Yes we can do more in practice, yes we can keep people out of hospital, yes we can really be that holistic ideal-but only with lots more time per patient. That of course means much smaller lists, lots more doctors, and in time perhaps less pay. At the moment it pays doctors to work too hard. That incentive may need to be removed. Graeme Mackenzie out of hours general practitioner North Cumbria graeme@papmacks.co.uk

Competing interests: None declared.

1 Heath I. Only general practice can save the NHS. BMJ 2007;335:183. (28 July.)

\section{Not with the state apparatus}

Heath believes that it is governments which are sapping the morale of general practitioners (GPs), by introducing the twin evils of markets and private profit. ${ }^{1}$ She forgets that it was the GPs themselves who agreed a new contract that abolished their commitment to 24 hour "social solidarity," while giving them better rewards.

The special role of primary care doctors in the United Kingdom is already sullied. The possibility of their recovery to a central "gatekeeping" role is offered by primary care commissioning. But the information technology and management add-ons make this peculiarly unattractive. Could it be the health service managers who are determinedly undermining the GPs' morale and esteem? The one continuous thread throughout the past 50 years of the NHS has been the desire of the state apparatus to "break the power" of doctors, and bring them to heel-while securing their own continued expansion of power and inefficiency.

L S Lewis general practitioner Surgery, Newport, Pembrokeshire SA42 OTJ

sam@garthnewydd.freeserve.co.uk

Competing interests: LSL is an NHS GP and a Socialist.

1 Heath I. Only general practice can save the NHS. BMJ 2007:335:183. (28 July.) 